\title{
Components of a learning model relating to health promotion for at-risk people of lifestyle diseases
}

\author{
Premwadee Sarisheewin ${ }^{1}$, Manaswas Kovitaya ${ }^{2}$, and Archanya Rattana-Ubol ${ }^{1,2 a}$ \\ ${ }^{1}$ Saraburi Public Health Office, Tambon Pak Pure, Muang Saraburi,18000 Thailand \\ ${ }^{2}$ Department of Lifelong Education, Faculty of Education, Chulalongkorn University, 254 Phayathai \\ Road, Wangmai, Pathumwan, Bangkok 10330, Thailand
}

\begin{abstract}
Obesity prevalence among people is increasing globally. Health Promoting Policy has been initiated in Thailand to tackle this problem. This qualitative study aimed to find out the components of a learning model from 2 best practice villages, focusing on 3 main issues - food, exercise, and emotion. Author uses in-depth interviews method and information was analyzed with content-analysis techniques in understanding key components of how to uplift health promotion. The findings comprise of 8 components: (1) Learning from problem identification, (2) Developing Health promotion policy, (3) Establishing health promotion community school, (4) Selecting learners/trainers of the community, 5) Learning from role models and Thai Wisdom, (6) Designing health promotion practices, (7) Taking actions, developing selfefficiency, and creating self-confidence with new practices, (8) Specifying standards of community health promotion and documenting the results. These findings are relevant to movements for Thai people to take a meaning perspective in looking after their heath.
\end{abstract}

Keywords: components of a learning model; health promotion; at-risk people of lifestyle diseases.

\section{Introduction}

Nowadays, obesity is a major national public health crisis and is a main cause of at-risk lifestyle diseases. Especially, Thailand ranks number 5 in Asia Pacific in term of the number of obese population for the group above 15 years old. This consists of 17 million people country-wide, yielding an annual death toll of over 100,000; and projected obesity growth at 4 million people per year. This situation has been summarised in the slogan

\footnotetext{
${ }^{a}$ Corresponding author: Patt762@gmail.com
} 
"Good Economy, Problemmatic Society, Unsustainable Development" (Office of the National Economics and Social Development Board, 2011). Health Promoting Policy has been initiated in Thailand to tackle this problem and enhanced the development of healthy ways of living among people. This health problem happens from malnutrition, inadequate exercise, and emotional instability, all of which are related to personal belief, value, and ways of life. As a result, most people are encountering at-risk lifestyle diseases. At present, there is no proper approaches to motivate people to change from within. Therefore, a learning model is the best tool to promote healthy ways of living by themselves. However, the methods used by this national policy and their efficiency have not been welldocumented.

All of these health issues needed to put control in order to build stability for healthy lifestyle as it is necessary to stabilize our human resources for development of the nation. The government has agreed to focus "People" as the centre for the country development by encouraging participation from the Thai people in the Government's National Economic and Social Development Plans (8th (1997-2001), 9th (2002-2006) and 10th (2007-2011) and continues to do so into the current plan,11th (2012-2015); according to Thailand Healthy Lifestyle Strategic Plan, B.E. 2554-2563 (2011-2020), includes three important sustainable life styles; sufficient food consumption, adequate exercise and proper emotional control. To achieve this, it is needed to change in attitude towards self-sustainable in lifestyle and towards recovering the Thai Wisdom for improvements in physical, mental, society and intellectual (Office of the National Economics and Social Development Board, 2008). It has been highlighted in the educational are as the major tool for the rediscovery of good health which corresponds to the National Education Act of B.E. 2542 (1999) sections 6 and sections 23 that indicates an integration of knowledge in order to achieve a balanced, harmonious, and sustainable lifestyle (Office of the National Education Commission, 2012). This is supported by section 8 of the Promotion of Non-Formal and Informal Education Act, B.E. 2551 (2008) that highlights the priority in life-long education in order to "acquire basic knowledge and skills for seeking the measurements that would facilitate learning throughout one's life" (Office of the National Education Commission, 2008).

For this reason, researcher wishes to study and develop the learning model to promote health based on the Thailand Healthy Lifestyle Strategic Plan deploying the combination of Thai Wisdom and Transformative Learning Process of Mezirow's theory which focuses on paradigm change in order to develop the three important sustainable lifestyles: sufficient food consumption, adequate exercises and proper emotional control. Currently, this study is on the first objective; to synthesize and analyze data to come up with factors to promote health based on the Thailand Healthy Lifestyle Strategic Plan using Thai Wisdom and Transformative Learning Process for people at-risk of lifestyle diseases. The first step of this study consists of the documentary review from theories, principles and also other related research papers as well as the field study from the best case villages. The methods used in this phase are participative observation, in-depth interview and focus group discussion with the experts. All of this information will be collected and analyzed in order to develop a learning model to promote health using Thai Wisdom.

Results from the first step of this study have shown that components of a learning model relating to promoting personal health are the key factors in order to create paradigm change which is aligned with Thai Wisdom, believe and life style. Moreover, these will be used as the guideline for the new meaning perspective development for decision making and for the new role determination to fit with three sufficient life styles: sufficient food consumption, adequate exercise and proper emotional control. 


\section{Objective}

To find out the components of a learning model relating to health promotion with the focus on 3 main issues - food, exercise, and emotion.

\section{Methodology}

This study employed qualitative approaches via a guideline of ten steps of Perspective Transformation Process proposed by Mezirow,[1-4] and Thailand Healthy Lifestyle Strategic Plan, B.E. 2554-2563 (2011-2020). The research methodology also consisted of documentary review from theories, principles, and also other related research papers as well as the field study at the 2 best case villages - (1) Phoraiwan district Amphoe Mueang, Phetchaburi (2) Donduang district Amphoe Banmi, Lopburi. The waistline criterias set for obese measurement are at $80 \mathrm{~cm}\left(32^{\prime}\right)$ or higher in females and $90 \mathrm{~cm}\left(36^{\prime}\right)$ or higher in males. The data was analysed and synthesized with content analysis to develop a draft of learning model to promote health base on the Thailand Healthy Lifestyle Strategic Plan using Thai Wisdom for at-risk people of lifestyle diseases.

\section{Result}

The result shows the eight components - (1) Learning from problem identification, (2) Developing Health Promotion Policy, (3) Establishing Health Promotion Community School, (4) Selecting learners/trainers of the community, (5) Learning from role models and Thai Wisdom, (6) Designing health promotion practices, (7) Taking actions, developing self-efficiency, and creating self-confidence with new practices, (8) Specifying standards of community health promotion and documenting the results. The contents of each component are as follow;

\section{(1) Learning from problem identification.}

The first step is to identify the current and common community issues about obesity. This will be the starting point to create the awareness of the problem in order to understand the actual needs of the community. For this step, the purpose is to create the awareness of the obesity concerns as the enhancing factors to health promotion.-disorientation dilemmas. The guiding questions are as follows:

1. What are the concerns or issues resulting from obesity problems?

2. What are the consequences or implications concerning the obesity problem?

(2) Developing health promotion policy.

The next step after acquiring the basic information about the obese implications is to develop the Health Promotion Policy via social networks based on Thailand Healthy Lifestyle Strategic Plan using Thai Wisdom to tackle on the increasing prevalence of a lifestyle diseases in line with 3 main behavioural risk factors-appropriate eating prevention, physical activity and emotional control.

(3) Establishing the health promotion community school.

To support the above policy, the Health Promotion Community School is required to set up as the center of sharing and learning relating to health promotion activities. This will be the community learning center for those people to share learning and have activities together.

(4) Selecting learners/trainers of the community.

To make this happens; we need to identify the target group who share the obesity problems. At the same time, we also need to identify who are going to be the trainers. Those trainers must have knowledge and experiences relating to the local Thai Wisdom. 


\section{(5) Learning from role models.}

To strengthen the learning and help encouraging, we need to identify the success role model as the idol to which the others can follow.

(6) Designing health promotion practices.

The next step is to develop the practical activities to fit with their contexts. This will be created according to their own needs and design as well as their interests according to the available resources. This is the crucial step to further develop their own local wisdoms.

(7) Taking actions, developing self-efficiency, and creating self-confidence with the new practices.

To make it as part of success, they need to practice to the level that they feel confidence with high internal integrity. Also, when considering the activities in this group focused on learning by the program participants and positive reinforcement, friends helping friends using repeatedly words as spell triggers and extracted to achieve self-confidence. Overtime, this will be further developed as part of their own habits.

(8) Specifying the standards of community health promotion and recording/documenting the results.

With the extensive practicing, we are certain that the adequate knowledge, learning and satisfied experiences will be achieved. The next step is to develop the policies and guidelines for the community in order to set up the new standard of living and to achieve the community Health Promotion Policy based on Thailand Healthy Lifestyle Strategic Plan using Thai Wisdom.

These findings show that the positive awareness of self-care learnings is important and this could be strengthened via social network through positive reinforcement each other. All these factors will be included in the contexts driven by Mezirow's 10 steps of perspective transformation which comprised of disorienting dilemma, self-examination, self-questioning, self-awareness, exploration of options for new roles, planning of a course of action, understanding of how to act, trying of new roles, positive feedback and reintegration [3].

At this point, we could summarize that all of at-risk people of lifestyle diseases delinquents started with their problems that made them unhappy from intrapersonal conflict. Until they confronted with disorienting dilemma, they could go through the fact of reality and need to explore their feelings.

\section{Conclusion}

These eight components are the key ingredients to develop a draft of learning model to promote health base on the Thailand Healthy Lifestyle using Thai Wisdom for at-risk people of lifestyle diseases and provide the foundation for community participation as well as change in behaviour concerning health. However, Transformative Learning theory, as outlined by Mezirow's theory, suggests that adult learning is spurred by a disorienting dilemma. Adults then use critical reflection and discourse prior to implementing new learning. Public healthcare incited that transformative learning has not been currently employed; therefore, this study has explored the using of transformative learning principles in healthcare promotion.

\section{References}

1. Mezirow, J., A critical theory of adult learning and education [Electronic version]. Adult Education, 32(1), 3-24, (1981). 
2. Mezirow, J., Contemporary paradigms of learning. Adult Education Quarterly, 46(3), 158-173. Retrieved September 2, 2008, from the SAGE Social Science Collections, (1996).

3. Mezirow, J., Transformative learning: Theory to practice [Electronic version]. New Directions for Adult and Continuing Education, 74, 5-12, (1997).

4. Mezirow, J. \& Associates, Learning as transformation. San Francisco, CA: JosseyBass, Inc., (2000).

5. Office of the National Economics and Social Development Board, Summarize the plan develops the economy and National social 1-10. Bangkok : The Prime Minister's office, (2006).

6. Office of the Ministry of Public Health., Thailand Healthy Lifestyle Strategic Plan (2011-2020); (http://bps.ops.moph.go.th/plan4year2/sumaporn/index.html - accessed December), (2009).

7. Office of the National Economics and Social Development Board, Plan Direction Develops that 11(the community), 11 Plans to Happiness social Havely the immunity. Bangkok: Siammit printing \& publishing Office, (2010).

8. Office of the National Economics and Social Development Board, The Plan Develops The Economy and National Social 11(2012-2016). Bangkok : the Prime Minister's office, (2012).

9. Office of the Ministry of Public Health, Central Regional Primary Health care. Nontaburi, (2012). 